\title{
A morphometric study of jugular foramen in adult dried human skull of South Karnataka population
}

\author{
Shashanka M J' ${ }^{1}$, Swaroop $\mathbf{N}^{2, *}$, Vishal Kumar ${ }^{3}$, Jagadish ${ }^{4}$ \\ ${ }^{1,2}$ Assistant Professor, ${ }^{3}$ Professor and HOD, Dept. of Anatomy, ${ }^{4}$ Statistician, Dept. of Community Medicine, Kodagu Institute of \\ Medical Sciences, Madikeri, Karnataka, India
}

*Corresponding Author:

Email: swaroopa.n12@gmail.com

\begin{abstract}
Introduction: The jugular foramen (JF) is larger irregular curved foramen situated in the skull base which transmits major neurovascular structures especially internal jugular vein. Variations in JF are more common in the same or different crania, races and sexes. The knowledge of detailed anatomy is therefore necessary to conduct microsurgeries in and around these foramina. Material and Methods: The present study was conducted on 40 adult dried human skulls having 80 jugular foramen procured from Department of Anatomy at Kodagu Institute of Medical Sciences, Madikeri .We have observed and metric measurements of the anterioposterior and mediolateral diameter of jugular foramen, width and depth of the jugular fossa were taken by using digital vernier callipers and the data were tabulated, analysed and compared.

Results: The dimensions of JF and Jugular fossa were larger on right side. Out of 40 skulls, bilateral complete septations were found in $6(15 \%)$ skulls and bilateral partial septations were found in $4(10 \%)$ skulls. Two septations on left side were observed in only one skull. The mean \pm SD of width and depth of jugular fossa were $7.61 \pm 1.95 \mathrm{~mm}$ and $8.63 \pm 2.58 \mathrm{~mm}$ on left and $9.18 \pm 1.65$ $\mathrm{mm}$ and $10.39 \pm 3.33 \mathrm{~mm}$ on right side respectively. A dome indicating the prominent superior jugular bulb were found in 69 (86.25\%) jugular fossa, of which 29 (72.5\%) were bilateral.

Conclusion: The variations could be due to constitutional, racial or genetic factors. Thus the present study is important for the surgeons in dealing with space occupying lesions in and around the foramen.
\end{abstract}

Keywords: Skull, Jugular foramen.

\section{Introduction}

Jugular foramen (JF) is bilateral large irregular opening in the base of the skull, with long axis directed forwards and medially. The anterior boundary is formed by jugular fossa of petrous temporal and posterior boundary being jugular notch of the occipital bone. The foramen is divided into 3 parts i.e., anterior, intermediate and posterior, with anterior part giving passage to inferior petrosal sinus, intermediate part mainly conveying glosso-pharyngeal, vagus and accessory nerves and posterior part transmitting internal jugular vein. ${ }^{1}$

During radical neck dissection, internal jugular vein being a dominant vein of the region, is often ligated which can leads to the risk of venous infarction. $\mathrm{JF}$ is affected in the following syndromes which can occur due to the Glomus tumors, Meningiomas, Schwannomas, Metastatic tumors located at the cerebellopontine angle, Trauma, Infections and other bone diseases involving middle ear and JF. Jugular foramen syndrome or Vernet's syndrome is characterised by the paralysis of the 9 th, $10^{\text {th }}$ and 11 th cranial nerves. Villaret's syndrome involves the above nerves, along with paralysis of the 12th cranial nerve, occurs due to retropharyngeal lesion invading the posterior cranial fossa. Jackson syndrome involves paralysis of vagus, accessory and hypoglossal nerves due to premature closure of sutures of skull. Schmidt syndrome involves vagus and accessory nerve paralysis. Tapia syndrome involves vagus and hypoglossal palsy occurs as a complication of general anaesthesia. $^{2}$

Treatment of choice for most of the above mentioned conditions is surgical resection. Nowadays with the advancement of microsurgical techniques, the removal of advanced Jugular foramen lesions is possible. With the detailed anatomical knowledge of this region, the neurosurgeons are becoming bolder enough to operate in and around this region. So the present study is done to provide morphometric details of JF which further helps neurosurgeons for their successful surgeries. ${ }^{3}$

\section{Material and Methods}

The present study was conducted on 40 adult dried human skulls having $80 \mathrm{JF}$ procured from Department of Anatomy, at Kodagu Institute of Medical Sciences, Madikeri. The deformed, damaged skulls, skulls of paediatric age were excluded from the study. The following parameters were observed and measured using digital vernier callipers with $0.1 \mathrm{~mm}$ precision. (Fig. 1).

a. Anterioposterior (AP) diameter of JF: Maximum Anterioposterior diameter of JF.

b. Mediolateral (ML) diameter of JF: Distance between medial most and lateral most points of JF.

c. Presence or absence of septations - if present noted the number.

d. Width of jugular fossa: Maximum width of jugular fossa. 
e. Presence or absence of dome in jugular fossa was noted

f. Depth of the jugular fossa: dome if present then the distance is measured between summit of the dome and the inferior border of jugular fossa.

The results were tabulated and compared on both the sides; the results were analysed using Unpaired T test with SPSS version 20. Our results were compared with previous studies.

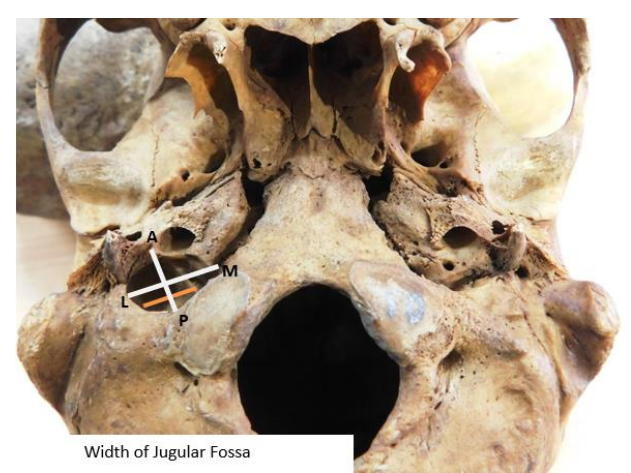

AP: Anterioposterior Diameter of JF

ML: Mediolateral Diameter of JF

Fig. 1: Showing the measurements of JF

\section{Results}

Out of 40 skulls having $80 \mathrm{JF}$ studied, the following observations were noticed.

Anterioposterior diameter of JF: On left side JF range and mean $\pm \mathrm{SD}$ was $4.8 \mathrm{~mm}$ to $10.4 \mathrm{~mm}$ and $7.45 \pm 1.34 \mathrm{~mm}$ respectively. On the right side $\mathrm{JF}$ range and mean \pm SD was $6.2 \mathrm{~mm}$ to $11.4 \mathrm{~mm}$ and $9.2 \pm 1.34$ $\mathrm{mm}$ respectively. AP diameter showing less than $5 \mathrm{~mm}$ were found in $1(1.25 \%)$ of JF, 5 to $10 \mathrm{~mm}$ were found in $66(82.5 \%)$ of $\mathrm{JF}$ and more than $10 \mathrm{~mm}$ were found in $13(16.25 \%)$ of JF.

Mediolateral diameter of JF: On left side JF range and mean \pm SD was $8 \mathrm{~mm}$ to $17.2 \mathrm{~mm}$ and $13.2 \pm 2.28$ $\mathrm{mm}$ respectively. On the right side JF range and mean \pm SD was $9.4 \mathrm{~mm}$ to $20 \mathrm{~mm}$ and $14.42 \pm 2.71 \mathrm{~mm}$ respectively. AP diameter showing less than $12 \mathrm{~mm}$ were found in $21(26.25 \%)$ of $\mathrm{JF}, 12$ to $17 \mathrm{~mm}$ were found in $48(60 \%)$ of JF and more than $17 \mathrm{~mm}$ were found in $11(13.75 \%)$ of JF.

Septations of JF: Out of 40 skulls, bilateral septations (complete/ partial) in JF were found in $13(32.5 \%)$ skulls, bilateral complete septations were found in 6 $(15 \%)$ skulls and bilateral partial septations were found in $4(10 \%)$ skulls. Out of $80 \mathrm{JF}$, septations were observed in $30(37.5 \%)$ out of which 15 were found having partial septas and 15 were found having complete septations. Only one skull showed two septations in JF on left side. The right side JF showed $16(40 \%)$ septations, of which $10(25 \%)$ were partial, 6 $(15 \%)$ were having complete septations. The left side JF showed $14(35 \%)$ septations of which $5(12.5 \%)$ were partial, $9(22.5 \%)$ were having complete septations.

Width of jugular fossa: The range and mean \pm SD of width of jugular fossa on left side, was $0 \mathrm{~mm}$ to 10.6 $\mathrm{mm}$ and $7.61 \pm 1.95 \mathrm{~mm}$ respectively. The range and mean $\pm \mathrm{SD}$ of width of jugular fossa on right side, was $5.4 \mathrm{~mm}$ to $13 \mathrm{~mm}$ and $9.18 \pm 1.65 \mathrm{~mm}$ respectively. Width of jugular fossa showing less than $5 \mathrm{~mm}$ were found in $6(7.5 \%)$ of $\mathrm{JF}, 5$ to $10 \mathrm{~mm}$ were found in 56 $(70 \%)$ of $\mathrm{JF}$ and more than $10 \mathrm{~mm}$ were found in 18 $(22.5 \%)$ of JF.

Dome of Jugular fossa: Out of $80 \mathrm{JF}$ a dome indicating the prominent superior jugular bulb were found in $69(86.25 \%)$ jugular fossa, of which 29 $(72.5 \%)$ were bilateral. The right side showed 38 $(52.17 \%)$ and on the left side showed 31 (47.83\%) domes.

Depth of the jugular fossa: The range and mean $\pm \mathrm{SD}$ of depth of jugular fossa on left side, was $0 \mathrm{~mm}$ to 15.1 $\mathrm{mm}$ and $8.63 \pm 2.58 \mathrm{~mm}$ respectively. The range and mean $\pm \mathrm{SD}$ of depth of jugular fossa on right side, was $1.9 \mathrm{~mm}$ to $15.3 \mathrm{~mm}$ and $10.39 \pm 3.33 \mathrm{~mm}$ respectively. Depth of jugular fossa showing less than $5 \mathrm{~mm}$ were found in $8(10 \%)$ of JF, 5 to $15 \mathrm{~mm}$ were found in 69 $(86.25 \%)$ of $\mathrm{JF}$ and more than $15 \mathrm{~mm}$ were found in 3 $(3.75 \%)$ of JF.

All the above mentioned measurements were larger on right side than left side, which showed a statistically significant $\mathrm{p}$ value $<0.01$ (Table 1 )

Table 1: Dimensions of Jugular foramen and Jugular Fossa

\begin{tabular}{|l|c|c|c|c|c|}
\hline \multirow{2}{*}{\multicolumn{1}{|c|}{ Parameters }} & \multicolumn{2}{c|}{ Right side } & \multicolumn{2}{c|}{ Left side } & p value \\
\cline { 2 - 6 } & Range & Mean \pm SD & Range & Mean \pm SD & \\
\hline AP. Dia - JF $(\mathrm{mm})$ & $6.2-11.4$ & $9.2 \pm 1.34$ & $4.8-10.4$ & $7.45 \pm 1.34$ & 0.0001 \\
\hline ML. Dia - JF (mm) & $9.4-20$ & $14.42 \pm 2.71$ & $8-17.2$ & $13.2 \pm 2.28$ & 0.0316 \\
\hline Width- Jugular fossa(mm) & $5.4-13$ & $9.18 \pm 1.65$ & $0-10.6$ & $7.61 \pm 1.95$ & 0.0002 \\
\hline Depth- Jugular fossa(mm) & $1.9-15.3$ & $10.39 \pm 3.33$ & $0-15.1$ & $8.63 \pm 2.58$ & 0.0056 \\
\hline
\end{tabular}

\section{Discussion}

The structures that traverses the JF are the sigmoid sinus, jugular bulb, inferior petrosal sinus, meningeal branches of the ascending pharyngeal and occipital arteries, the 9 th -11 th cranial nerves with their ganglia, the tympanic branch of the glossopharyngeal nerve, the auricular branch of the vagus and the cochlear aqueduct. The difficulties in exposing this canal are created by its deep location and the surrounding vital structures, such as the carotid artery anteriorly, the 
hypoglossal nerve medially, the facial nerve laterally and the vertebral artery inferiorly. All these important structures require careful dissection during access to this canal. ${ }^{2}$

The size and shape of the jugular foramen is related to the size of the internal jugular vein and the presence or absence of a prominent superior bulb. The right foramen is usually larger than the left. There is a very wide variation in the anatomy of the intra cranial venous sinuses which accounts for variation in size and shape of jugular foramen. The difference in size of the two internal jugular veins is already visible in the human embryo at the $23 \mathrm{~mm}$ stage and probably results from differences in the pattern of development of the right and left brachiocephalic veins. ${ }^{4}$

The present study is similar with the study conducted by Anjali Singla et $\mathrm{al}^{5}$ in having higher AP and ML diameters of JF on right side than left and was statistically significant $(\mathrm{p}<0.01)$. The studies conducted by Roma Patel ${ }^{3}$, Ekinci and Unur, ${ }^{6}$ Shruthi $\mathrm{BN}^{4}$ and Hussain $\mathrm{Saheb}^{7}$ reported lesser and study done by Idowu $^{2}$ showed higher AP and ML diameters of JF than the present study. There was no statistical significance on right and left side of JF in studies conducted by Pereira $\mathrm{GAM}^{8}$ and Idowu $^{2}$ and had reported high ML diameter of JF on left side than right which is reversed in the present study. (Table 2)

Table 2: Comparison of Dimensions of Anterioposterior (AP) diameter and Mediolateral Diameter with Previous studies

\begin{tabular}{|c|l|c|c|c|c|c|}
\hline Sl & \multicolumn{1}{|c|}{ Authors } & Year of & \multicolumn{2}{|c|}{ AP dia } & \multicolumn{2}{c|}{ ML dia } \\
\cline { 4 - 7 } No. & & Study & Right & left & Right & left \\
\hline 1 & Ekinci and Unur $^{6}$ & 1997 & $8.4 \mathrm{~mm}$ & $7.6 \mathrm{~mm}$ & $16 \mathrm{~mm}$ & $15.5 \mathrm{~mm}$ \\
\hline 2 & Idowu $^{2}$ & 2004 & $10.22 \mathrm{~mm}$ & $9.57 \mathrm{~mm}$ & $13.90 \mathrm{~mm}$ & $14.11 \mathrm{~mm}$ \\
\hline 3 & ${\text { Hussain Saheb et } \mathrm{al}^{7}}^{7}$ & 2010 & $7.83 \mathrm{~mm}$ & $6.83 \mathrm{~mm}$ & $23.62 \mathrm{~mm}$ & $22.86 \mathrm{~mm}$ \\
\hline 4 & Pereira, GAM $^{8}$ & 2010 & $9.21 \mathrm{~mm}$ & $8.65 \mathrm{~mm}$ & $15.82 \mathrm{~mm}$ & $15.86 \mathrm{~mm}$ \\
\hline 5 & Anjali singla et al $^{5}$ & 2012 & $9.32 \mathrm{~mm}$ & $7.34 \mathrm{~mm}$ & $15.67 \mathrm{~mm}$ & $14.85 \mathrm{~mm}$ \\
\hline 6 & $\begin{array}{l}\text { Roma Patel and } \\
\text { C.D.Mehta }\end{array}$ & 2014 & $7.9 \mathrm{~mm}$ & $6.2 \mathrm{~mm}$ & $12.17 \mathrm{~mm}$ & $11 \mathrm{~mm}$ \\
\hline 7 & Shruthi B.N et al $^{4}$ & 2015 & $7.51 \mathrm{~mm}$ & $7.16 \mathrm{~mm}$ & $24.48 \mathrm{~mm}$ & $21.24 \mathrm{~mm}$ \\
\hline 8 & Present study & 2018 & $9.2 \mathrm{~mm}$ & $7.45 \mathrm{~mm}$ & $14.42 \mathrm{~mm}$ & $13.2 \mathrm{~mm}$ \\
\hline
\end{tabular}

The present study differs a lot from the study conducted by other authors in terms of percentage of partial and complete septations of JF on right and left side (Table 3). Bilateral complete septations were found in $6(15 \%)$ skulls and bilateral partial septations were found in $4(10 \%)$ skulls. Partial septations were more on right JF than left JF in our study which were similar to the studies done by Roma Patel ${ }^{3}$ and Shifan Khandey. ${ }^{9}$ Complete septation were more on left JF than right JF which had not been reported in studies conducted by other authors. Regarding the morphogenesis of foraminal anomalies at the base of the skull, three major fenestrations were observed in early human foetal skull - foramen lacerum anteriorhiatus between greater and lesser wing of sphenoid; foramen lacerum medius-opening between basisphenoid and periodic capsule; foramen lacerum posterior-hiatus between basiocciput and auditory bullae. These large fenestrations become subdivided by the ingrowth of bony spicules, leading to the formation of multiple foramina. Foramen lacerum posterior persists as JF. Variations in the septations of JF are attributed to variability in bone formation around primitive foramen lacerum posterior, indicating the ongoing evolutionary process. ${ }^{5}$

Table 3: Comparison of septations with previous studies

\begin{tabular}{|c|l|c|c|c|c|}
\hline $\begin{array}{c}\text { Sl } \\
\text { No. }\end{array}$ & \multicolumn{1}{|c|}{ Authors } & \multicolumn{2}{c|}{ Complete septations } & \multicolumn{2}{c|}{ Partial septation } \\
\cline { 3 - 6 } & & Right & left & Right & left \\
\hline 1 & Hatiboglu and Anil $^{11}$ & $5.6 \%$ & $4.3 \%$ & $2.6 \%$ & $19.6 \%$ \\
\hline 2 & Sturrock R.R $^{10}$ & $3.2 \%$ & $3.2 \%$ & $1.3 \%$ & $10.9 \%$ \\
\hline 3 & Patel and Singel $^{12}$ & $23.1 \%$ & $17.6 \%$ & $19.5 \%$ & $59.3 \%$ \\
\hline 4 & Hussain Saheb et al $^{7}$ & $20.8 \%$ & $16.8 \%$ & $45.6 \%$ & $58.4 \%$ \\
\hline 5 & Shifan Khanday et al $^{9}$ & $13 \%$ & $4 \%$ & $24 \%$ & $7 \%$ \\
\hline 6 & $\begin{array}{l}\text { Roma Patel and } \\
\text { C.D.Mehta }\end{array}$ & $16 \%$ & $14 \%$ & $29 \%$ & $25 \%$ \\
\hline 7 & Present study $^{3}$ & $15 \%$ & $22.5 \%$ & $25 \%$ & $12.5 \%$ \\
\hline
\end{tabular}


The percentage of dome on left side were more on right than left JF in the present study, which were similar with the studies conducted by other authors compared and we also found maximum number of bilateral dome $(72.5 \%)$ which had not been reported so far in the previous studies. (Table 4).

Table 4: Comparison of Dome of Jugular foramen with previous studies

\begin{tabular}{|c|l|c|c|c|c|}
\hline Sl & \multicolumn{1}{|c|}{ Authors } & $\begin{array}{c}\text { Presence of } \\
\text { dome bilateral }\end{array}$ & $\begin{array}{c}\text { Presence of dome } \\
\text { on right side }\end{array}$ & $\begin{array}{c}\text { Presence of dome } \\
\text { on left side }\end{array}$ & $\begin{array}{c}\text { Absence } \\
\text { of dome }\end{array}$ \\
\hline 1 & Sturrock R.R $^{10}$ & $53.9 \%$ & $30.1 \%$ & $6.4 \%$ & $9.6 \%$ \\
\hline 2 & Hatiboglu and Anil $^{11}$ & $49 \%$ & $36.1 \%$ & $4.6 \%$ & $10.3 \%$ \\
\hline 3 & Patel and Singel $^{12}$ & $21 \%$ & $38.5 \%$ & $14.3 \%$ & $25.2 \%$ \\
\hline 4 & Anjali singla et al $^{5}$ & $66 \%$ & $6 \%$ & $16 \%$ & $12 \%$ \\
\hline 5 & Present study & $72.5 \%$ & $11.25 \%$ & $2.5 \%$ & $13.75 \%$ \\
\hline
\end{tabular}

The average width and depth of jugular fossa in the present study was found to be $9.18 \mathrm{~mm}$ and $10.39 \mathrm{~mm}$ on right and $7.61 \mathrm{~mm}$ and $8.63 \mathrm{~mm}$ on left respectively. Anjali singla et $\mathrm{al}^{5}$ reported in their study that the average width and depth of jugular fossa as $8.99 \mathrm{~mm}$ and $11.11 \mathrm{~mm}$ on right and $7.54 \mathrm{~mm}$ and $11.04 \mathrm{~mm}$ on left jugular fossa respectively. The width of jugular fossa in the present study was almost similar to the study compared, but the depth of jugular fossa showed significant difference in having high right sided measurements in the present study. The variation in the dimensions of jugular fossa may be related to high jugular bulb causing conductive hearing loss because of its contact with tympanic membrane causing interference with ossicular chain and finally resulting in the obstruction of round window niche. The high jugular bulb may also cause complications during cochlear implantation due to its encroachment to middle ear space and due to its intimate relation with the internal acoustic meatus needs atmost cautious approach while performing surgeries for vestibular schwanommas. $^{5}$

\section{Conclusion}

The present study observed the variation in the size of JF. The foramen are larger on the right than the left in south Karnataka population. These variations in the size, shapes and compartments of jugular foramen might be a part of the ongoing evolutionary process, also involving racial and genetic factors. Detailed anatomical knowledge of morphology, compartments and morphometry is necessary for neurosurgeons and ENT surgeons to have a bolder approach in dealing with space occupying lesions in and around the jugular foramen.

Funding: No funding sources.

Conflict of interest: None declared.

\section{Acknowledgements}

Our sincere thanks to the Dean, Head and Faculty of Department of Anatomy, Kodagu Institute of Medical Sciences, Madikeri, for their valuable suggestion, help, support and permission to conduct the study on adult human dried skull of the institution. Also we are thankful for the first MBBS students of 2017-18 batch for rendering the skulls needed for study purpose.

\section{References}

1. AK Dutta .Essentials of Human Anatomy Part II 5th edition, Current Books International 2009;57.

2. Idowu OE. The jugular foramen-A morphometric study. Folia Morphol 2004;63:419-22.

3. Roma Patel, C.D. Mehta. Morphometric study of Jugular Foramen at base of the skull in South

4. Gujarat region. IOSR J Dent Med Sci 2014;9:58-61.

5. Shruthi B.N, Pavan P. Havaldar, Shaik Hussain Saheb, Henjarappa K S . Morphometric Study of Jugular Foramen. Int J Integrative Med Sci 2015;2(10):164-66.

6. 5.Anjali Singla, Daisy Sahni,Anjali Aggarwal, Tulika Gupta, Harjeet Kaur. Morphometric Study of the Jugular Foramen in Northwest Indian Population. J Postgraduate Med Educ Res 2012;46(4):165-71.

7. Ekinci N., Unur E. Macroscopic and morphometric investigation of the jugular foramen of the human skull. $J$ Anat 1997;72:525-29.

8. Hussain Saheb S, Mavishetter G F, Thomas S T, Prasanna L C, Muralidhar P. A Morphometric study of the jugular foramen in human adult skulls of south India. J Biomed Sci and Res 2010;2(4):240-43.

9. Pereira GAM, Lopes PTC, Santos AMPV, Krebs WD. Morphometric aspects of the jugular foramen in dry skulls of adult individuals in Southern Brazil. J Morphol Sci 2010;27:3-5.

10. Shifan Khanday, Ramesh Kumar Subramanian, Melani Rajendran, Ashfaq Ul Hassan, Sajad Hamid Khan. Morphological and morphometric study of jugular Foramen in south Indian population. Int $J$ Anat Res 2013;1(3):122-27.

11. Sturrock RR, Variations in the structure of the jugular foramen of the human skull. J Anat 1998;160:227-30.

12. Hatilboglu MT, Anil A. Structural variations in the jugular foramen of the skulls. J Anat 1992:180:191-96.

13. Patel MM, Singel TC. Variations in the structure of jugular foramen of the human skull in Saurashtra Region. J Anat Soc India 2007:56 (2):34-37.

How to cite the article: J Shashanka, N. Swaroop, Vishal Kumar V., Jagadish. A morphometric study of jugular foramen in adult dried human skull of South Karnataka population. Indian $J$ Anat Surg Head Neck Brain 2018;4(3):82-85. 